\title{
International Students in Higher Education: A Follow-up Study of University Graduates
}

\author{
AMY E. ZELMER* and NEIL A. JOHNSON
}

\begin{abstract}
Despite current concern about declining foreign student enrolments in Canadian post-secondary institutions, there remains a paucity of information regarding international students' perceptions and performance after returning to their own countries. To assist in overcoming this deficiency, this paper reports about methodological procedures, results and research and policy implications from an investigation of CIDA graduates who had studied at the University of Alberta between 1972 and 1984. A range of substantive outcomes are presented: educational attainments and characteristics of students; marital and family circumstances; preferred programs of study; use of and satisfaction with university facilities; academic and personal interaction; prior and subsequent employment; adjustments to Canada; advantages and disadvantages accruing from studying in Canada; as well as comments about the experience and advice for prospective international students. The findings had policy implications relating to correction of imbalances according to gender, nationality and employment background of students, as well as to provision for academic, personal, recreational and financial needs of international students. Suggestions are also made about data collection emphases, strategies for establishing and maintaining contact with informants, and productive avenues for future inquiry.
\end{abstract}

\section{RÉSUMÉ}

Malgré les inquiétudes que suscite actuellement la baisse des inscriptions d'étudiants étrangers dans les établissements postsecondaires canadiens, il y a pénurie d'informations sur les perceptions des étudiants internationaux et sur leurs résultats après leur retour dans leur pays. Dans le but de combler cette lacune, le présent article rend compte des démarches méthodologiques, des résultats et des implications pour la recherche et les politiques à partir d'une étude faite auprès de

*Associate Vice President (Academic), University of Alberta

$\dagger$ Doctoral student and Intern to the President and Vice President (Academic), University of Alberta

ACKNOWLEDGEMENT: Lawrence Kaida assisted with the development and distribution of questionnaires for the study. 
diplomés de l'ACDI qui ont étudié à l'Université de l'Alberta, entre 1972 et 1984. Une gamme de constations indépendantes y est présentée: réalisations et caractéristiques éducationelles des étudiants; situation conjugale et familiale; programmes d'études préferés; utilisation des installations universitiares et satisfaction à leur endroit; interaction personnelle et universitaire; emploi avant et après les études; ajustement au Canada; commentaires sur l'expérience et conseils aux futurs étudiants internationaux. Les conclusions ont affecté les politiques pour réduire les disproportions relatives au sexe, à la nationalité et aux antécédents d'emploi des étudiants, ainsi que les moyens de répondre aux besoins des étudiants internationaux en matière d'ensignement et de loisirs ainsi qu'à leurs besoins personnels et financiers. Des suggestions sont également faites sur l'importance de recueillir les données, sur des méthodes en vue d'établir et de maintenir le contact avec les informateurs, et sur des moyens efficaces d'obtenir des renseignements à l'avenir.

As Canadian universities and colleges continue to educate significant numbers of students from other countries, legislators and post-secondary policy makers alike grapple with the thorny issue of provision of higher education services for foreign students. Debates have proliferated in Canada - as they have in other developed countries - about the optimal numbers of international students, with attention being focused on costs and benefits accruing from admission of overseas students as well as on questions of international cooperation and development (Canadian Bureau for International Education (CBIE), 1981, 1986a, 1986b; Council of Ministers of Education, 1986; Fox, Humphries \& Lewis, 1987; North-South Institute, 1985; Overseas Students Trust, 1987; University of Toronto, 1986; Williams, Woodhall \& O'Brien, 1986). As a result of national and provincial government attention, new policies for international students have been proposed with some regularity, and many universities and colleges in Canada have been both exhorted and keen to increase the numbers and variety of international students on their campuses. At the same time, as a CBIE report recently recorded, there has been an almost $20 \%$ cumulative decline in foreign student intake since 1981-82 (CBIE, 1987; Globe and Mail, 1987); and this trend has led to Canadian Government commitments to expand Canadian International Development Agency (CIDA) funding for foreign students, relax employment restrictions, introduce promotional initiatives, and conduct two studies of current and past students, all with the intention of reversing the decline in international student enrollments (Government of Canada, 1987a, 1987b). Of course, for the post-secondary institutions, such protracted argument and confusion over policy only complicates existing concerns about organizational size, balance and funding and intrudes upon internal discussions about educational purpose and responsibility.

Other confounding issues, such as that of enhancing educational opportunity for women, have also intervened in these debates. For example, CIDA recently 
reported that "women from Third World countries are four times less likely than men to get money from Ottawa to study in Canada" (Edmonton Journal, 1987); in 1986 only $21 \%$ of international students brought to Canada as trainees or students were female. And, as a senior CIDA policy analyst was said to have remarked, "if you want to do effective development you have to include 100 per cent of the population."

If post-secondary educational institutions in this country are to provide adequate and equitable training programs for international students, their planning must accommodate the needs and interests of students and of the countries they represent. More specifically, if undergraduate and graduate programs are to be adapted to equip international students with appropriate intellectual and practical skills and to further the process of development overseas, then policy makers in universities and colleges need to inform themselves about the work backgrounds, experiences, attitudes and problems of current and past international students, as well as about what effects those Canadian experiences have in the years following graduation.

Limited information is now available on the numbers and characteristics of international students in Canadian post-secondary institutions. However, the literature currently has little advice for those who assume responsibility for recruitment and selection of overseas candidates, planning of appropriate programs, allocation of financial assistance, and counselling for graduates intending to return home to take up employment. By way of example, we remain uncertain about the suitability of programs that immerse international as well as Canadian students in local culture and technology with little or no attention to differing expectations, needs and facilities in other locales. It was this deficiency of information that motivated a preliminary follow-up study of CIDA scholarship holders from the University of Alberta and the investigative procedures, results, and research and policy implications of this study form the subject of this paper.

\section{Purposes of the Study}

Studies of international students at university have been conducted intermittently over the years at the University of Alberta and in other Canadian and overseas locations (e.g., Bryan \& Holdaway, 1987; Burke, 1986; Galet, 1976; International Student Centre, Queen's University, 1987; Mickle \& Chan, 1986; von ZurMuehlen, 1985; Zikopoulos \& Barber, 1985). The usual practice, however, has been to probe demographic characteristics and current attitudes and concerns of students who are "on site" and in the midst of their studies - an approach that, of course, has obvious advantages associated with cost and access to respondents and statistical data. For example, Bryan and Holdaway recently surveyed 1577 students by means of the University of Alberta's campus mail system, and elicited responses about students' activities and experiences from $53 \%$ of that number. On the other hand, these and other researchers have tended to avoid the more difficult but equally important route of examining attitudes and experiences subsequent to students' completion of studies and return home. Indeed, the recent proposal by 
the Secretary of State to attract international students to Canada encompassed plans to pursue investigation not only of current students but, as a separate study, of attitudes and performance of graduates who now reside once again in their own country. Such avenues of inquiry could have new insights to contribute, for they could provide a different, more far-sighted and reflective perspective on the Canadian educational experience than has generally been obtained, and they may also furnish information on the appropriateness of Canada's post-secondary programs and institutional services for graduates returning to different employment and social contexts. This study was planned with that intent.

Our plan was to study the employment and educational backgrounds, university and Canadian experiences, and subsequent occupations of a selected group of financially assisted international students who had completed studies at the University of Alberta during the preceding 12 years. We hoped that, as a result of this and similar investigations, university and college decision makers, funding agencies and others interested in Canada's role in international education and development might be informed about the strengths and deficiencies of existing programs and institutional facilities and about the needs of international students, as an aid in formulating policies for the future.

This inquiry was also designed with an associated contribution in mind. As noted, there is little research evidence available on international students that has attended to outcomes of Canadian experiences and to students' subsequent reflections on that stage in their lives and careers. An obvious explanation for this deficiency in the literature is the difficulty of eliciting responses from diverse regions of the world and at a time when many potential respondents have lost contact with, and perhaps immediate interest in, their Canadian institutions. Investigators need to pursue studies of this follow-up kind, however, in order that the feasibility and efficacy of alternative data collection techniques can be tested and debated. Although the findings from the study described here were handicapped by response rate difficulties, much was learned about the nature of those problems and about useful strategies for conducting follow-up studies in international students' home countries. One conclusion that needs to be noted immediately is that detailed information about students' experiences and concerns - as was provided by the respondents in this inquiry - is arguably of more value than sketchy, generalizable findings from a statistically representative aggregation of respondents. Some suggestions for future research in this domain are also advanced in this paper.

\section{Methodology}

Of the 15,787 international students who have attended the University of Alberta during the period 1972-1984, 133 have been financially supported on CIDA traineeships. Because of administrative requirements of these traineeships, comprehensive student records including "permanent addresses" have been maintained at the university. In the hope of establishing contact with a large proportion of international students from developing countries, this pool of former 
students was chosen as the basis for a follow-up study. As a consequence, the population for this preliminary study comprised all international students who, with CIDA's financial assistance, had completed undergraduate or graduate programs at the University of Alberta during the period 1972-84. It was expected that almost all of these students would have returned to their own or other countries and have resumed employment in their chosen fields. Addresses were available for 129 of the graduates; a further four, about whom no information was available, had to be excluded from the study. The geographic dispersal of CIDA graduates necessitated data collection by means of mailed questionnaires, and these were posted in March 1985.

As noted above, a particular problem encountered in this kind of study is the mobility of potential respondents; and, in this regard, the present study was no exception. For example, the "permanent" addresses on file proved to be of limited use, particularly in relation to students who had graduated more than one or two years prior to the investigation.

With this constraint in mind, a number of strategies were used in an effort to maximize the questionnaire returns. Initially, we provided a self-addressed return envelope as well as international postage reply coupons, a brief outline of recent events at the University of Alberta, and an offer of further information if requested. The questionnaire was designed to be as non-threatening as possible; we were conscious that some graduates may be reticent about responding to a questionnaire, about criticizing a funding agency, university or culture, or about disclosing mediocre achievement following graduation. To this end, anonymity of responses was guaranteed; the questionnaires were pre-numbered, but this served only to check on returns, and the principal investigator kept the key to respondents' names in confidence.

Three further steps were also taken in an effort to maximize returns:

1. The alumni association at the university was approached to obtain current addresses. Unfortunately, this association had not been active in following overseas graduates and was therefore of only limited assistance.

2. Wherever possible, we contacted the supervisors of graduate students to check whether there had been ongoing contact. This first required a search of theses to identify supervisors.

3. A follow-up aerogram was sent to all respondents who had not responded within two months of the original mailing.

\section{Results}

As anticipated the response rate was low: of 129 questionnaires distributed, 28 usable responses were received $(22 \%)$, one more was unusable, 14 were returned unclaimed and in one instance we were notified that the graduate was deceased. This might be interpreted as 28 usuable responses $(25 \%)$ out of a total of 114 questionnaires thought to have been received. This low response rate probably results in part from the difficulties of the various national postal systems, bearing in mind that most addresses were in developing countries. We were unable to 
determine what a normal base line might be for delivery to a mailing list like ours, but personal experience would lead us to expect that some of the questionnaires were neither delivered nor returned. One should also bear in mind that the response rate for a questionnaire to international students still on campus (Bryan \& Holdaway, 1987) was only 53\%.

There are several additional possible explanations for individuals' failures to respond, each of which would have some effect upon the representativeness of the respondents:

a) some individuals may have left their initial post-graduation employment for better individual opportunities in other countries. Given the length of the time period involved they may then have become 'unknown' at their former address. Such changes of employment may be evidence of the 'brain drain' phenomenon or may indicate a lack of employability in the country of origin once the sponsoring CIDA project had been completed;

b) some may have been displaced by political upheavals or other phenomena unrelated to their actual employment performance;

c) some who believed themselves to have been less successful than they had hoped may have been reluctant to respond to the questionnaire;

d) some who were dissatisfied with their university experience may have been reluctant to respond.

Even with the low response rate, much was learned from the exercise, both substantively and with regard to methodological concerns. It is noteworthy that many of the respondents conveyed great enthusiasm about the study by commenting extensively on many issues of personal concern and by requesting copies of the report findings and other information about the university. Nevertheless, the findings reported below should be viewed as indicative of experiences and attitudes prevailing among many overseas students but they may not necessarily be representative of CIDA students or of international students in general.

A profile of respondents, based on sex and country of residence and citizenship prior to University of Alberta's studies, approximated the appearance of those attributes in the population surveyed. The overwhelming majority of respondents $(24 ; 86 \%)$ was male, as was the case with the total group $(89 \%)$. At the time of the investigation, 17 respondents $(61 \%)$ were in their $30 \mathrm{~s}$; ten more $(36 \%)$ were between 40 and 49 , and one was in his twenties. By far the largest representation of nationalities in the study was Tanzania ( 9 respondents, 33\%; 39 in the population, $30 \%)$, followed by Zambia $(3,11 \% ; 13,10 \%)$, Nigeria $(3,11 \% ; 10,8 \%)$ and Ghana $(2,7 \% ; 12,9 \%)$. This geographic distribution reflects both a major geographic focus of CIDA during the period covered by the study and the direction of students from English-speaking backgrounds into a university which uses English as the language of instruction; the experience of francophone students in other Canadian universities could be significantly different.

The small number of women in the student population is probably a result of the 
selection of students by field of study and is also influenced by the fact that the period covered by the study was prior to the adoption by CIDA of specific initiatives with regard to women in development. Unfortunately the very small number of female respondents makes it impossible to say anything meaningful about the ways in which their experience may have differed from that of the male students.

While we judged representativeness of this kind to be less than critical in such a study, the figures presented here do afford a reminder about the imbalance of sexes that currently exists among these Canadian-funded and perhaps also other international students.

The questionnaire used in this study attended to a variety of issues associated with international students' attitudes and experiences prior to, during and following their studies in Canada. The following summary of findings deals in turn with educational attainments and characteristics, marital and family circumstances, University of Alberta programs, use of and satisfaction with university services, academic and personal interaction, previous and subsequent employment, adjustment to Canada, advantages and disadvantages of studying in Canada, the Canadian experience overall, and advice for intending international students.

\subsection{Educational Attainments and Characteristics}

The 28 respondents reported having obtained a total of 33 degrees from the University of Alberta. In total, however, they had also completed 56 prior or subsequent post-secondary educational qualifications at other institutions - most frequently in Tanzania, the United Kingdom, Nigeria, and elsewhere in Canada. Indeed, at the time of the survey, 26 respondents had satisfied requirements for masters' degrees at the University of Alberta or other institutions; most often these were in Science. Five had also completed doctoral programs.

These CIDA award holders tended to be not only highly educated but efficient in completing their programs. The 28 respondents had obtained a total of 89 qualifications, $69(78 \%)$ of which had been completed within four years and a further ten $(11 \%)$ in the fifth year of study.

\subsection{Marital and Family Circumstances}

At the time of attending the University of Alberta, almost equal numbers of these respondents were married (15) and unmarried (13). Moreover, 13 of the married students recorded having children - five had three children each, and three students had four each. Although marital, family and financial commitments did not deter five of the international students from traveling to and residing in Canada with their spouses and children, others were forced to take more traumatic options. Seven of the married students with children elected to study alone in Canada, and the spouse of another arrived later. Reasons given for spouses and children not accompanying students to Canada included insufficient financial resources, current employment of spouse, and children at school in the home country. 


\subsection{University Programs}

Eleven of these international students came to the University of Alberta to pursue undergraduate studies (4 B.Ed.; 4 B.Sc.; 1 B.Comm.). The greater number, however, had obtained their CIDA funding for graduate programs. Most popular were masters' degrees in Science or Agriculture, which spanned specializations in animal physiology, farm structures and environmental control, food processing, hydrogeology, petroleum reservoir engineering, production agricultural economics, and water pollution control. Five respondents had graduated with masters' degrees in education, focusing their attention on curriculum and instruction, educational administration, industrial and vocational education, and secondary mathematics education. The three M.B.A.'s included specializations in accounting, and one student had taken an M.A. with particular emphasis on physical planning and computers. The two University of Alberta doctorates awarded related to studies of development economics and mathematics education.

\subsection{University Services: Use and Satisfaction}

The University of Alberta, like many large post-secondary institutions, provides a range of accommodation, health, personal and recreational services for students. With regard to housing, the University maintains extensive and varied living facilities for international and other students. Low-cost student housing is available for students with spouses, students with children, and single students; the latter have the alternative of sharing houses or accepting room and board in halls of residence. The international students in this study had taken advantage of the whole array of housing services offered by the university; some had also tried private rental accommodation, either shared or alone. Despite the small numbers who had experienced each location, opinions about the standard and suitability of this service for international students were generally positive; asked to rate their accommodation on a scale from "unsatisfactory" through "adequate" and "good" to "excellent," respondents tended to favour "good" as their level of satisfaction.

In an effort to gauge the adequacy and appropriateness of the many other facilities provided for international students, respondents were invited to rate their frequency of use and level of satisfaction or dissatisfaction with the following 11 campus services: Office of International Student Affairs, CIDA co-ordinator, University Health Service, student clubs, Students' Union, Graduate Students' Association, Student Help (telephone service), Student Counselling, chaplains, departmental counsellors, and faculty counsellors. Response categories on "frequency of use" included "did not know it existed," "knew about but never visited," "visited once or twice" and "visited frequently." Satisfaction was rated on a five-point scale from 1 , "very unsatisfactory," to 5, "very satisfactory."

Most students were at least aware of the various services available, although not all services were frequently used. Taken collectively, they were judged to be generally satisfactory, although again there were marked differences in satisfaction levels for the 11 services. Predictably, the most frequently used resource of all for these students, and one that gained high satisfaction responses, was the CIDA 
International Students in Higher Education:

Table 1

Actual and Preferred Levels of Contact with Faculty Members,

Canadian and International Siudents. and the Community

\begin{tabular}{|c|c|c|c|c|c|c|c|c|}
\hline \multirow[b]{2}{*}{ Level of Contact } & \multicolumn{2}{|c|}{ Eaculty Members } & \multicolumn{2}{|c|}{ Canadian Students } & \multicolumn{2}{|c|}{ International Students } & \multicolumn{2}{|c|}{ Community } \\
\hline & f & $\% f$ & $\mathrm{f}$ & $\% \mathrm{f}$ & $\mathrm{f}$ & $\% \mathrm{f}$ & $\mathrm{f}$ & $\% \mathrm{f}$ \\
\hline \multicolumn{9}{|l|}{ Actual $(n=28)$} \\
\hline Very little & 4 & 14.3 & 2 & 7.1 & 2 & 7.2 & 5 & 17.9 \\
\hline Some & 8 & 28.6 & 5 & 17.9 & 3 & 10.7 & 18 & 64.3 \\
\hline Moderate & 9 & 32.1 & 15 & 53.6 & 13 & 46.4 & 4 & 14.3 \\
\hline Great Deal & 7 & 25.0 & 6 & 21.4 & 10 & 35.7 & 1 & 3.5 \\
\hline \multicolumn{9}{|l|}{ Preferred ( $n=25$ ) } \\
\hline Much less & - & - & - & - & 1 & 4.0 & - & - \\
\hline Somewhat less & 1 & 4.0 & - & - & 1 & 4.0 & 3 & 12.0 \\
\hline Same amount & 7 & 28.0 & 8 & 32.0 & 13 & 52.0 & 4 & 16.0 \\
\hline Some more & 14 & 56.0 & 13 & 52.0 & 6 & 24.0 & 14 & 56.0 \\
\hline Much more & 3 & 12.0 & 4 & 16.0 & 4 & 16.0 & 4 & 16.0 \\
\hline
\end{tabular}

co-ordinator. Five students did not know of International Student Affairs - a result that may be attributable to the relatively recent inception of this service for overseas students. Moreover, the majority of students (being aware of it) visited International Student Affairs often, and there was overwhelming support for this service. Student clubs and associations were known to all respondents and were used to varying degrees. Satisfaction with these organizations, however, was mixed; in particular, a majority was dissatisfied with the Graduate Students' Association. Most were aware of the various personal counselling centres on campus; most, however, used the services of Student Counselling (18 students), Student Help (18) and the chaplains (13) only "once or twice" - although some who did so found the campus chaplains helpful. Many students did not know departmental and faculty counsellors exist. Others used this source of academic and personal assistance rarely; and the strongest satisfaction ratings on these services were "neutral" - neither satisfied nor dissatisfied.

\subsection{Academic and Personal Interaction}

Respondents were asked to rate their actual and preferred levels of contact with faculty members, Canadian students, international students, and the wider community. Results appear in Table 1. Each domain of interaction experienced was rated on a four-point scale from "very little" to a "great deal," while for preferences a five-point scale from "much less" to "much more" was used.

Responses about contact with academic staff spanned the rating scale provided. Although most students had at least some exposure to faculty members, the majority would have appreciated more of this kind of contact. The international 
Duration of the Job Immediately Prior to and All Jobs (Including

Current Position) Following University of Alberta Auendance

(no. respondents $=28$; total no. jobs $=89$ )

Before Attending University of Alberta ${ }^{1}$

$\begin{array}{ll}1 \text { year } & 7 \\ 2 \text { years } & 6 \\ 3 & 5 \\ 4 & 1 \\ 5 & 3 \\ 6 & - \\ 7 & - \\ 8 & 3 \\ 9 & 1\end{array}$

After Leaving University of Alberta ${ }^{2}$

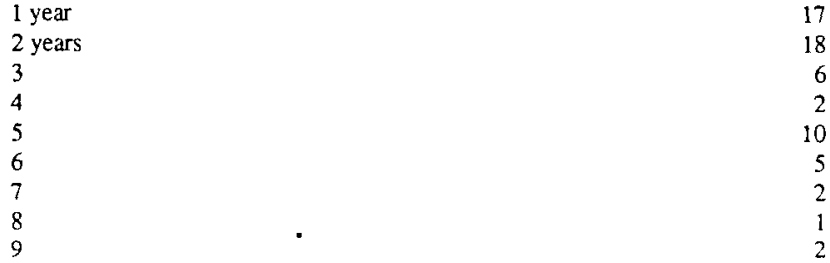

1. 2 respondents reported no previous employment.

2. 1 respondent had just returned home; no subsequent employment at the time of the study.

students tended to have a moderate degree of contact with Canadian as well as other international students and they expressed a preference for greater involvement with those from Canada. A substantial majority indicated having had only limited ("some") contact with members of the wider community and expressed a desire for further interaction of this type.

\subsection{Prior and Subsequent Employment}

The most distinctive aspect of this study - and therefore, probably the most important - was its attention to international students' employment before and after studying at the University of Alberta. We elicited data that revealed employment patterns and permitted speculation about causal connections among employment, selection for receipt of financial assistance, and subsequent employment opportunities and advancement.

As Table 2 shows, many of these CIDA award holders had spent little time in their positions prior to University of Alberta studies. It would be reasonable to conclude, then, that they had been identified early as suitable award recipients and/or that they had been actively pursuing scholastic and professional advance- 
ment up to the time of their application for study abroad. This finding may also be an artifact of the traineeship program which often provides this type of assistance as a part of a larger CIDA project, usually with the intent of having nationals prepared to continue the activity at the end of the CIDA project. These explanations are supported by the figures on duration of subsequent appointments: most scholars were promoted, not only on their return, but again after only one or two years of service.

It is also worth noting that 20 of the 28 respondents returned to their previous employers following studies at the University of Alberta. Only five immediately took up positions in new organizations. (Two of these, who graduated at an early stage, accepted positions in Canada - an option that is no longer available.) A further two respondents took up their first appointment after the CIDA award, and one had 'only just returned at the time of the survey and had no subsequent employment to record. This pattern of returning to equivalent employers did not, however, mean that the overseas employing agencies failed to recognize and capitalize upon the newly acquired expertise of returning graduates; on the contrary, Table 3 indicates that the University of Alberta degree seemed to have both immediate and long-term implications for respondents' work. Fifteen graduates resumed work commitments at an equivalent standing, but ten were elevated immediately to positions of apparently higher status and responsibility; for two graduates, return from Canada also brought initial, high-level employment.

The long-term employment situation also exhibited a clear and positive career pattern. At the time of the study, approximately half of the students (14 of 27) were working in jobs of the same kind and level as when they had first returned. Despite the short period between the completion of graduate studies and this investigation, however (between one and 12 years after), almost half of these graduates (13 of 27) had either acquired different, all apparently more senior, positions within their own countries (11) or established themselves as private consultants there (2). The teachers and post-secondary instructors who received CIDA funding for study in Canada serve as a clear example. Of the ten who left work and home for study abroad, only three returned to be teachers; four became lecturers, one a researcher, one a professor, and one an administrator. By the time of data collection for this study, only one of the ten was still teaching; one had become a high-level planner, and five were now in administrative posts. Responses to open-ended questions also lent clear support to this conclusion; the following accounts are indicative:

My U. of A. education was a major turning point in my professional career. Canadian education is well recognized in ... [country].

My education is Canadian; the depth of experience received has placed me in an area by myself. I am able to make significant contribution to ... [chosen field] in my country and region. National planning in these areas have [sic] brought me in contact with agencies like UNESCO, CIDA ... [and other prestigious international organizations] and even World Bank Missions. I consider myself a $\mathrm{U}$ of $\mathrm{A}$ ambassador. 
Table 3

Type of Job Immediately Prior to and Immediately Following University of Alberta Allendance, and Current Job (no. respondents $=27)^{l}$

\begin{tabular}{|c|c|c|c|c|c|c|c|c|c|c|}
\hline \multirow[b]{2}{*}{ Prior Job } & \multicolumn{10}{|c|}{ Subsequent Job (no. employed) ${ }^{2}$} \\
\hline & Techn & $\begin{array}{l}\text { FldWkr } \\
\text { /Officer }\end{array}$ & $\begin{array}{l}\text { Tchr/ } \\
\text { lnsuctr }\end{array}$ & $\begin{array}{l}\text { Lect- } \\
\text { urer }\end{array}$ & $\begin{array}{l}\text { Prof } \\
\text { AsscPrf }\end{array}$ & Reschr & Planner & $\begin{array}{l}\text { Agric. } \\
\text { Ecnmst }\end{array}$ & $\begin{array}{l}\text { Cons- } \\
\text { ultant }\end{array}$ & $\begin{array}{l}\text { Admnr } / \\
\text { Supvsr }\end{array}$ \\
\hline 1. No employment & & & & & & $1(1)$ & & & & $1(1)$ \\
\hline 2. Technician & 1 & & & $1(2)$ & & & $1(1)$ & & & \\
\hline $\begin{array}{l}\text { 3. Field Worker } \\
\text { /Officer }\end{array}$ & & $2(1)$ & & & & $1(1)$ & & & & (1) \\
\hline $\begin{array}{l}\text { 4. Teacher/ } \\
\text { Instructor }\end{array}$ & & . & $3(1)$ & $4(2)$ & 1 & $1(1)$ & (1) & & & $1(5)$ \\
\hline 5. Lecturer & & & & 4 & (2) & & & & (1) & (1) \\
\hline 6. Assistant Professor & & & & & $1(1)$ & & & & & \\
\hline 7. Researcher & & & & & & $1(1)$ & & & & \\
\hline 8. Planner & & & & & & & 1 & & (1) & $1(1)$ \\
\hline $\begin{array}{l}\text { 9. Administrator } \\
\text { /Supervisor }\end{array}$ & & & & & & & 1 & (1) & & \\
\hline
\end{tabular}

The MBA degree [in Canada] is a warrant for highly competitive managerial posts. I was selected to be a Board member for the ... Corporation in 1980, at the age of 30. Thereafter I have been General Manager and at present Deputy General Manager of ... Company. ... It is a unique experience. I still expect to rise higher. All this because of $\mathrm{U}$ of $\mathrm{A}$ !!

Table 4 provides an indication of the types of employers which first lost the services of the award recipients and then gained direct benefit from the graduates' new-found knowledge, experience and talents. Of 27 respondents, 24 were university or government employees; two more had not yet been employed; and only one had come from private industry.

Four free-response questions in the instrument also brought a variety of comments about cultural adjustments required to cope adequately in Canada, benefits, problems and other effects of studying at the University of Alberta, the Canadian experience, and advice for prospective international students. 
Table 4

Type of Employer With Whom Working Immediately Prior to and Immediately Following University of Alberia Attendance and in Current Job (no. respondents $=27)^{l}$

Prior Employer

Subsequent Empoyer (no. employed) ${ }^{2}$

University Government Private Industry

$\begin{array}{ll}\text { 1. University } & 6(4) \\ \text { 2. Government } & 1(1) \\ \text { 3. Private industry } & \\ \text { 4. Not employed } & \end{array}$

$6(4)$

(1)

(1)

$1(1)$
(2)

1. 1 respondent (a planner in government) had just returned home; no subsequent employment at the time of the study, so not included.

2. Free-standing numbers indicate initial employer after completing studies at the University; numbers in parentheses indicate current employer.

\subsection{Adjustment to Canada}

The question on adjustment attracted responses spanning many issues - food, housing, finances, climate, family, and the Canadian cultural experience in general. Some students considered that the local culture had involved no significant adjustment; for others it was recalled as a personally rewarding experience, especially for those students who had tried to approach the new cultural setting with open minds. Indeed, one student found the major problem to be with other international students: "I had more cultural differences with international students than with Canadians." Again, Canadian foods presented no difficulty for many students, although funding constraints curtailed the choices of accommodation and eating habits of others. Indeed, adequacy of CIDA's financial support was a common concern; in particular, cost-of-living corrections were thought to be insufficient for living and studying in Edmonton. Some respondents were fortunate enough to have supplementary assistance from their own governments, and this was appreciated. Six respondents commented favourably on the University's housing facilities; such comments were countered, however, by statements about unavailability of preferred accommodation and noise in halls of residence. Families at home were sorely missed by students who had been obliged to come alone to Canada; the families likewise suffered from the absence of one spouse and parent. Students' most frequent comments concerned the Canadian climate; eight adapted quickly to the new weather conditions, but one took a year to adjust, another blamed the winter weather for tension and poor health, and ten more complained more generally about the difficulty of coping with the local climate. 


\subsection{Advantages and Disadvantages of Studying in Canada}

When asked to record advantages and disadvantages of studying in Canada, half of the respondents cited the broadening influence of university courses on their existing knowledge. Nine also made direct reference to the outcome of obtaining higher-level positions at home as a result of studying abroad; and three were grateful for the effect of improving their teaching skills. The educational and social experiences were also said to have increased individuals' self-confidence and professional attitudes, added a new dimension to their personal lives, and diminished inter-cultural ignorance and barriers. In addition, the experience alerted students to important cultural differences; and this realization was thought to be a valuable learning outcome. As a result of interaction with people of many cultures, they "realized and appreciated values in one another's cultures." One respondent summed up the outcomes of her Canadian study in this way: "I have advanced more rapidly in my career. My outlook on life has been broadened. I can accept cultural difference easier [sic] and I have a wider field from which to choose my life goals/ambitions."

Six students noted with regret that no substantial adjustments had been required of them. On the other hand, others cited marked cultural differences as a source of concern. Other problems were associated with the return home. After studying in Canada, respondents experienced difficulty in adjusting to attitudes of colleagues and to the frustration of returning to poorly organized workplaces, inadequate facilities, reduced work opportunities and inconvenience of lower socio-economic conditions at home. As one student expressed it, "After I had stayed in an affluent society for about 5 years, it was a little bit difficult to adjust to conditions of developing countries." And, after four years away from Canada, another respondent commented, "I still have problems readjusting myself to the life in my country." A third was particularly discouraged: "My U of A experience heightened my sense of despair at the inadequate educational facilities and lack of concrete support for research in our Universities. It also [highlighted] ... apparent organizational lapses and inertia at the campus and [in] the nation at large." Some respondents had also discovered that jealousy caused colleagues to block their promotions. Others found it difficult to apply their skills in their own countries although one respondent contended instead that the graduate's responsibility is "not to transplant what you have learned, but rather to select what you think is appropriate and useful to the environment."

\subsection{The Canadian Experience}

The overall experience of Canadian study was overwhelmingly judged to be a positive one for the international students. Nineteen respondents recalled how they had enjoyed the city of Edmonton and the opportunity to interact with its people. An equal number commended the University of Alberta for its excellent teaching and research; four made specific reference to the quality of the University's facilities. In more general terms, six other students referred to their study in Canada as "productive" and "intellectually stimulating" - an experience that can 
"change opinions and the way of work." This experience had given five students the requisite skills for exercising leadership at home, and six expressed an interest in returning to this Canadian setting for further study. At the same time, there were isolated adverse remarks, relating to language problems, racial prejudice, the inappropriateness of examination procedures and an undue emphasis on facts in some courses.

\subsection{Advice for Prospective International Students}

In connection with a request for suggestions to other intending students, nine respondents strongly supported this university and the notion of study in Canada. One statement is indicative: "I believe it is always positive to study and live in a different environment which gives the chance to learn, understand and experience a different culture." This respondent continued by commending the high scholastic standard of the Canadian institution attended. More specific recommendations were to find accommodation close to the educational institution, to take advantage of the exceptional facilities available, and to make the most of the opportunity to be integrated into Canadian society. They were also cautioned to "work hard" to make the most of such a rare privilege and educational opportunity. Future students were, however, advised to journey to Canada only with sponsorship or with adequate financial resources in hand, and to acquaint themselves with Canadian history and culture and develop a facility with the English language beforehand.

\section{Discussion}

Although the number of responses in this investigation was small, important insights may be gained both from the results and from the investigative procedures used and problems encountered in the study. Attention should be given first to substantive issues arising from the foregoing summary of findings; these outcomes and implications may assist policy makers, resource administrators and program planners as well as providing additional evidence to inform the debate about education of international students in Canada.

Both the respondent group and the survey population of CIDA students were predominantly male - even more so than the national average cited earlier. The Alberta situation, therefore, seems to reflect the Canadian scene as a whole, and policies and incentives at the national level as well as program initiatives at the level of the individual institution may be required to give women a greater role in international studies and development. Funding authorities and institutional selection committees may also need to consider the nationalities of applicants for international study and awards. In this investigation, there was a substantial imbalance in the countries represented; if prospective development and extensive international relations efforts are deemed to be of consequence, then currently under-represented nations should be approached to enlist their interest and to obtain the names of suitable applicants for assistance.

Although the rewards of Canadian higher education for international students 
may be considerable, and although many students may not let their marital/family status keep them from such a professional and social opportunity, this study demonstrated that the students with families sometimes pursue those choices at the cost of great personal deprivation and family dislocation. Inevitably, the prospect of family separation must also deter many other intending applicants. Some, of course, do come to Canada for extended periods without their children and without their spouses. For them, problems such as that of spouses' employment at home may not be easily overcome; and some international students may prefer the continuity of schooling at home rather than the reorientation and uncertainty that attends new experiences in a different cultural and educational environment. Another prevalent reason for studying in Canada alone, however, is inadequacy of financial resources. This problem, together with some students' apparent insufficiency of funds for adequate housing and personal provision, signals a need to reassess current funding arrangements (such as the differential fee structure for foreign students) to alleviate the personal trauma and inevitable educational disadvantage caused by protracted geographic isolation from families. And it is encouraging that national legislators are now taking steps in this direction by giving students and spouses greater opportunities for work while in Canada.

The academic specializations of respondents in this study had obvious practical implications, particularly for third world countries. There was also a close association between these students' educational interests and subsequent employment; and from this we may reasonably infer a clear and practical intention among the recipients of CIDA awards. In this light, funding agencies may well regard educational and developmental intentions of future students as an important and reasonable criterion for judging applicants for assistance.

Housing facilities at the University of Alberta were generally rated as satisfactory. Students also seemed to be both aware of and reasonably satisfied with other services on that campus. Nevertheless, to be sure about the suitability of these services for international students, facilities at each Canadian institution would need to be assessed. Beyond general patterns in those perceptions, the responses about specific student services obtained in this study seem to have a message for student organizers as well as central administrators in many Canadian higher education institutions. International students may not be well served by existing provisions of student clubs and associations; special strategies may need to be developed to meet their needs and to accommodate them within the larger student campus. For university administrators - at least those at the University of Alberta and probably elsewhere - CIDA co-ordination (for those affected) and health services appear to fulfill an important purpose for international students. However, personal and academic counselling arrangements may not always be well used and may be less valuable than services such as those directed through international students' offices. From this it seems reasonable to infer that institutions may best serve their international students if they recognize and accommodate their distinctive needs by channeling personal and academic 
counselling services through an international students' unit, rather than relying solely upon the more conventional and all-inclusive avenues of academic and student counselling services. Two matters that may require special attention at this institutional level are provision of support following arrival, and assistance with the trying time following graduation. Students in this study encountered most problems in the first year, hence, effort needs to be expended to assist international students with the transition and initial concerns. And the social, professional and personal readjustment required of students upon their return to the home setting may require programs (as is now the case at the University of Alberta) to prepare students for that traumatic second transition.

Respondents' similar ratings of contact with Canadian and other international students and a preference for still further interaction with Canadians run counter to a belief that is sometimes asserted - that international students like to limit their contacts to associations with students of similar cultural origin. Indeed, institutional program developers may be well advised to arrange social activities with the intent of integrating international and local students rather than focusing on activities that emphasize segregation; and opportunities could be created to expose international students to local community groups and individuals. Hence, while universities may best cater for the counselling and other individual personal needs of international students through specialized international student affairs units, they may enhance ongoing, informal interaction with Canadian and other students and community members by providing integrated programs that promote cross-cultural contact.

With regard to the important matter of employment and Canadian study, the close connection between early selection of candidates for CIDA awards and the pattern of quick promotion upon their return home implies that CIDA is choosing well who to finance and/or that the opportunity to study in Canada is of considerable career benefit for the individual and of socio-economic importance for the country concerned. Although these elite individuals may have contributed substantially in their own countries even without Canadian qualifications and experiences, it seems likely from the evidence documented here that the financial outlay to bring them to study in Canada was a major contributor to the apparently high quality of their performance and to the attendant recognition accorded those graduates following their return home. Of course, the fact that the respondents almost all returned to the same countries and organizations reflects a likely immediate benefit in the overseas work setting. On the other hand, countries from which these students came also face some attrition - a "brain drain" - as is evidenced in the two respondents in this study who obtained jobs (and citizenship) in Canada; in such instances, the benefit of those skilled services accrues instead to Canada. Even so, it seems reasonable to conclude that the opportunity to pursue studies in Canada is an important determinant of career advancement and of the contribution that the individuals concerned make to progress in their own countries. 
In view of the importance of private industry to national growth in third world as well as developed countries, it was surprising to find in the results of this study an over-representation of awards to employees of public instrumentalities.

Adjustment to the Canadian lifestyle does not seem to impose unreasonable demands on international students. Climatic and dietary factors may present problems - if unavoidable ones - for some; and information for intending students is therefore important. More concerning is a perceived deficiency of funding to meet everyday needs. For this reason, policy makers may be well advised to consider not only expanding allotments of resources to entice more foreign students but maintenance of a reasonable level of material support for those who accept the challenge of studying in Canada. Recently announced legislative reforms may allow some students and their families to obtain funds; however, the high priority issue of uninterrupted study demands a reasonable level of support from international student awards.

Finally, students involved in this study were particularly supportive of the idea of international study in Canada. For them any personal, financial or academic problems seemed to be outweighed by subsequent realization of the enormous personal growth, professional advancement and opportunity for economic and social development occasioned by their studies abroad. It is students such as these, who can reflect upon their experience with the benefit of hindsight, who need to be approached for opinion and support by countries seeking accelerated growth and improved international relations. The study and subsequent employment experience seems likely to make such graduates among those best placed to inform future policy making, advise prospective students, and promote the goal of increased international student enrollment in Canada. To date, this resource appears not to have been adequately utilized.

Further to these substantive findings, certain methodological implications arise from the outcomes of and problems attending this research initiative. Based on the experience of this study, a range of suggestions for future research can be posited.

The most critical concerns in follow-up investigations with international students are those of obtaining current addresses and stimulating respondents' interest in supplying requested data. Despite the measures taken in this study to maximize the response rate, we found that, after as little as one or two years away from Canada, many international students cease regular contact with their institutions; occupations and addresses change, and communication becomes unreliable. Indeed, if the very enthusiastic responses received and the abundance of undeliverable mail items in this study can be used as a guide, it would seem that obtaining access to the respondents - rather than engaging their interest and cooperation - is the major barrier to surmount.

When contemplating research of the kind conducted here, certain strategies may be usefully employed. During the course of international students' programs in Canada, institutional reserachers need to make personal contacts with those potential respondents and to collect preliminary data on prior employment, current experiences and attitudes about studies and life in their new cultural situation. Not 
only can such contacts be used to obtain the students' perspective on international education, but opportunities would be provided both to identify problems requiring institutional attention and to establish associations that will enhance the quality and depth as well as the quantity of data collected, in succeeding years. At the conclusion of graduates' programs but prior to their departure from Canada, those respondents should be contacted again to request ongoing cooperation in forwarding up-to-date postal details and invited responses about the international study experience and subsequent employment. To further cement those connections, it is then incumbent on institutional representatives to commence written correspondence with those graduates and to provide periodic institutional updates.

Of course, the place of a strong alumni association or other formal structure which maintains regular contact and solicits changes of address and employment cannot be over-emphasized. In this way, researchers who wish to pursue follow-up studies of international students - and, indeed, of Canadian graduates - can be confident of reaching intended respondents and of engaging their interest in contributing to investigations. It is worth adding here that some alumni associations preserve links with foreign graduates through intermittent regional reunions of alumni; such activities are to be encouraged.

Researchers also need to consider the nature and intent of their inquiries. One way to maintain regular communication and to build a useful data base for ongoing research and comparison is to conduct annual or biennial surveys, perhaps commencing even before the arrival of intending students in Canada, and continuing in a programmatic manner for perhaps ten years afterwards. Appropriately designed instruments could thereby be used for acquiring and accumulating data on all aspects of international students' expectations, experiences and shortand long-term reflections upon Canadian and home studies, employment and personal attitudes. Such a program of research would facilitate temporal comparisons of perspectives as well as furnishing information on the strengths and shortcomings of programs, the personal and professional costs and benefits of international study for the students, and the impact of that experience for economic development in the students' own countries.

We also contend that the emphasis of data collection for these purposes should be on individual, detailed responses. A most valuable aspect of the study described here was the free-response data provided by respondents; this proved particularly useful for understanding perspectives based on long-term reflection upon international students' educational and career experiences. To this end, we advocate the development of research instruments which rather than eliciting only structured, superficial responses on predetermined issues, give respondents substantial freedom to express the feelings, attitudes, impressions and concerns that they consider to be paramount.

One further dimension may also be important for future inquiry in this domain. The study described in this paper focused on the benefit of post-secondary education for foreign students and their countries. However, if we are to understand the international student phenomenon in its widest context, research 
attention will also need to be directed toward examination of the contribution that international students make to social, cultural and economic progress in Canada and to the enhancement of international cooperation and understanding.

\section{REFERENCES}

Bryan, W.M. \& Holdaway, E.A. (1987). Report of the survey of international students at the University of Alberta: Winter session 1986-87. University of Alberta, Edmonton.

Burke, B.D. (1986). Experiences of overseas undergraduate students. Bulletin No. 18, University of New South Wales Student Counselling and Research Unit, Sydney.

Canadian Bureau for International Education. (1981). The right mix: Report of the Commission on Foreign Student Policy in Canada. Ottawa: CBIE.

Canadian Bureau for International Education. (1986a). Closing the door? A statistical report on international students in Canada: 1983-1985. Ottawa: CBIE.

Canadian Bureau for International Education. (1986b). International students and Canada's foreign policy. International Education Magazine (CBIE), 2(2), 6, 18-19.

Canadian Bureau for International Education. (1987). National report on international students in Canada, 1986-87. Ottawa: CBIE.

Council of Ministers of Education, Canada. (1986). Foreign students in Canada, vol. 1, A statement of issues for policy consideration. Toronto: CMEC.

Edmonton Journal. (1987, November 19). Overseas study grants discriminate, agency says.

Fox, J. with Humphries, J. \& Lewis, B. (1987). Canada and international student mobility: Where to now? Ottawa: Canadian Bureau for International Education.

Galet, A. (1976). CIDA survey - University of Alberta. Report for the Canadian International Development Agency, University of Alberta, Edmonton.

Globe and Mail. (1987, November 6). Endangered students.

Government of Canada. (1987a). For whose benefit? Report of The Standing Committee on External Affairs and International Trade on Canada's Official Developmental Assistance Policies and Programs ("The Winegard Report"). Ottawa: Queen's Printer.

Government of Canada. (1987b). Backgrounder to benefit a better world. Response of the Canadian Government to the Report of The Standing Committee on External Affairs and International Trade (No. 87-103), Ottawa.

International Centre, Queen's University. (1987). A study of international students at Queen's University: 1976/77-1985/86. Report, Queen's University at Kingston.

Mickle, K. \& Chan, R. (1986). The cross cultural adaptation of Hong Kong students at Canadian universities. Report prepared for the Canadian Bureau for International Education, Ottawa.

North-South Institute. (1985). Foreign students in Canada: A neglected foreign policy issue (Briefing Paper). Ottawa: North-South Institute.

Overseas Students Trust. (1987). The next steps: Overseas student policy into the 1990s. London: Shell.

University of Toronto. (1986). Report of the Presidential Task Force on Foreign Students. Report, University of Toronto.

von Zur-Muehlen, M. (1985). Country profiles of international students at Canadian educational institutions - 1979-80 to 1984-85 (Working Paper 85-1). Ottawa: Canadian Higher Education Research Network.

Williams, G., Woodhall, M. \& O'Brien, U. (1986). Overseas students and their place of study: Report of a survey. London: Overseas Students Trust.

Zikopoulos, M. \& Barber, E.G. (eds.). (1985). Profiles: Detailed analysis of the foreign student population: 1983/84. New York: Institute of International Education. 